\title{
A case of transient constrictive pericarditis in a 42-year old patient
}

\author{
Jasna Cmrečnjak, Branko Ostrički', Andrej Pal ${ }^{2}$, Tanja Marčec', Marina Gradišer ${ }^{1}$ \\ ${ }^{1}$ Čakovec County Hospital, Čakovec, Croatia \\ ${ }^{2}$ Varaždin General Hospital, Varaždin, Croatia
}

Constrictive pericarditis classically presents as a progressive and debilitating condition characterized by pericardial fibrosis, with or without calcification'. This results in chronic refractory congestive heart failure for which pericardiectomy is often required. Until relatively recently, the development of constrictive physiology was presumed to be irreversible ${ }^{2}$. However, in the past two decades there have been reports describing transient forms of constrictive pericarditis that have been resolved without surgical intervention. The development of constrictive hemodynamics and subsequent resolution with medical therapy (transient constrictive pericarditis) was first described by Sagrista-Sauleda et a $\beta$ in 1987. The authors suggested that mechanism responsible for the fin. dings in these patients was transiently thickened and inelastic pericardium resulting from edema, fibrin deposition or inflammation.

We present a case of 42-year-old man with a one-month history of fatigue and exertional dyspnea who came to our ER department complaining of abdominal discomfort accompanied by anasarca. There were no specific changes on initial ECG, the values of troponin T were normal and NT-proBNP slightly increased. On presentation, he was normothermic, tachycardic with normal first and second heart sounds and without audible pericardial rub. Jugular veins were markedly distended with positive Kussmaul's sign and hepatomegaly.

A transthoracic echocardiogram revealed abnormal ventricular septal motion - septal bounce, respiratory variation in ventricular size, biatrial enlargement and presence of a dilated inferior vena cava without inspiratory collapse. The Doppler flow velocity measurements revealed exaggerated respiratory variation (more than $25 \%$ ) in both mitral inflow velocity and tricuspid-mitral inflow difference. LV EF was normal and there weren't any signs of pulmonary hypertension or pulmonary valve stenosis. E/E" was 5 .

Chest MSCT revealed thickened pericardium (8-16 $\mathrm{mm}$ ) especially surrounding right ventricle without signs of calcification. There was also a moderate-sized right pleural effusion present with associated compressive atelectasis. Patient refused cardiac catheterization. With subsequent diagnostic work-up we excluded restrictive cardiomyopathy, primary liver disease, pulmonary hypertension and lung disease. The etiology of pericardial constriction was not established but idiopathic or postviral cause seemed likely.

Patient was treated with diuretics and salt restrictive diet to relief fluid overload and peripheral oedema. Significant clinical improvement was seen following 4 weeks of treatment with regression of edema, ascites, hepatomegaly and pleural effusion. Control echocardiography revealed resolution of constrictive hemodynamics according to flow velocity measurments as well as regresion of vena cava inferior and hepatic vein dilation.

KEYWORDS: transient constrictive pericarditis, thickened pericardium, septal bounce.

Received: $20^{\text {th }}$ Mar 2013
*Address for correspondence: Županijska bolnica Čakovec, I. G. Kovačića 3a, HR-
40000 Čakovec, Croatia.
Phone: +385-40-375-318
E-mail: jcmrec@ gmail.com

\section{Literature}

1. Haley JH, Tajik AJ, Danielson GK. Transient constrictive pericarditis: causes and natural history. Am J Cardiol. 2004;43:271-5.

2. Engel PJ, Fowler NO, Tei CW, et al. M-mode echocardiography in constrictive pericarditis. J Am Coll Cardiol. 1985;6:471-4.

3. Sagrista-Sauleda J, Permanyer-Miralda G, Candell-Riera J, Angel J, Soler-Soler J. Transient cardiac constriction: an unrecognized pattern of evolution in effusive acute idiopathic pericarditis. Am J Cardiol. 1987;59:961-6. 